Canadian Journal of Fisheries and Aquatic Sciences

Canadian

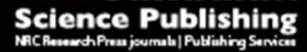

Journal canadien des sciences halieutiques et aquatiques

\title{
Getting Quantitative about Consequences of Cross- Ecosystem Resource Subsidies on Recipient Consumers
}

\begin{tabular}{|r|l|}
\hline Journal: & Canadian Journal of Fisheries and Aquatic Sciences \\
\hline Manuscript ID & cjfas-2016-0242.R1 \\
\hline Manuscript Type: & Article \\
\hline Date Submitted by the Author: & 21-Jul-2016 \\
\hline Complete List of Authors: & $\begin{array}{l}\text { Richardson, John; University of British Columbia, } \\
\text { Wipfli, Mark; University of Alaska Fairbanks, Department of Biology and } \\
\text { Wildlife }\end{array}$ \\
\hline Keyword: & Allochthonous inputs, detritus, fish, resource pulse, subsidy \\
\hline & \multicolumn{2}{|l}{} \\
\hline
\end{tabular}

SCHOLARONE ${ }^{\text {IM }}$

Manuscripts 
1 Getting Quantitative about Consequences of Cross-Ecosystem Resource Subsidies

2 on Recipient Consumers

3

4 John S. Richardson ${ }^{1}$, Mark S. Wipfli ${ }^{2}$

5

6 1 John.Richardson@ubc.ca, Department of Forest and Conservation Sciences, the University of

7 British Columbia, Vancouver, B.C., V6T 1Z4, Canada.

8 22mwipfli@alaska.edu, US Geological Survey, Alaska Cooperative Fish and Wildlife Research

9 Unit, Institute of Arctic Biology, University of Alaska Fairbanks, USA

10

11

12

13

14

15

16

17

18

19

20

21

22

23

24

25 
Abstract

Most studies of cross-ecosystem resource subsidies have demonstrated positive effects on

28 recipient consumer populations, often with very large effect sizes. However, it is important to

29 move beyond these initial addition-exclusion experiments to consider the quantitative

30 consequences for populations across gradients in the rates and quality of resource inputs. In our

31 Introduction paper to this special issue, we describe at least four potential models that describe

32 functional relationships between subsidy input rates and consumer responses, most of them

33 asymptotic. Here we aim to advance our quantitative understanding of how subsidy inputs

34 influence recipient consumers, and the communities they are part of. In the papers following,

35 fish were either the recipient consumers or the subsidy as carcasses of anadromous species.

36 Advancing general, predictive models will enable us to further consider what other factors are

37 potentially co-limiting (e.g. nutrients, other population interactions, physical habitat, etc.) and

38 better integrate resource subsidies into consumer-resource, bio-physical dynamics models.

40 Keywords

41 Allochthonous inputs, detritus, fish, resource pulse, subsidy 


\section{Introduction}

The importance of cross-ecosystem resource subsidies has been recognised in a variety of ecosystems for decades. Leaf detritus or dissolved organic matter entering freshwater food webs, sea wrack decomposing on beaches, salmon returning from the oceans to freshwater, and the emergence of the adult stages of aquatic insects are all well-studied examples of crossecosystem resource subsidies. However, the synthesis of the topic by Polis et al. (1997) helped

focus on the process and allowed for generalisations of this particular consumer-resource interaction across ecosystems. There is now theory available that allows for more formal consideration of population and community dynamics in response to these spatially subsidised, donor-controlled resource fluxes (e.g. Yang et al. 2008; Holt 2008; Takimoto et al. 2009). We now know that relative differences in primary productivity between adjacent habitats is not a sufficient predictor of which direction across ecosystem boundaries will result in impacts of subsidies on productivity of recipient consumers (Marczak et al. 2007a). However, if one considers directly comparable resource types (e.g. specific sizes of terrestrial prey and not simply all terrestrial prey), focussing on consumer-specific trophic levels and not just overall productivity, it will allow evaluation of the contributions of subsidies to recipient populations (Marczak et al. 2007a).

There have been a very large number of studies of the impacts of cross-ecosystem resource subsidies on recipient populations and communities (see Polis et al, 1997; Richardson et al. 2010). A long history of observation of the roles of subsidy inputs over the past century has evolved to a more quantitative approach, but there are still ways that this field can become more quantitatively predictive to test more refined hypotheses. In this introduction to our special issue we suggest possible advances from qualitative predictions about the responses to resource 
66 subsidies (e.g., simply predicting increases), to predicting the magnitude of changes in

67 productivity or population numbers of particular recipient populations. This would serve to

68 facilitate empirical tests of the quantitative contributions of spatially subsidised, donor-controlled

69 resources to population and community dynamics. In this paper we briefly review some

70 examples of the progress made in recent decades towards understanding the consequences of

71 resource subsidies for populations of recipient consumers, and ways in which our predictions

72 from hypotheses could be more quantitative. In the second half of the paper we introduce the

73 papers included in this special issue, and then end with considerations of ideas to serve as

74 guidance for future research.

Consumer responses to natural variation in subsidy input rates

Many studies have noted the importance of cross-ecosystem resource subsidies, from

observations of terrestrial prey in consumer stomachs to the large numbers of obligate

79 detritivorous organisms in freshwaters (e.g., Polis et al. 1997). Such observations have many

80 decades of history. In the past several decades, more and more studies have observed that in

81 general populations of consumers are more abundant or productive where subsidy inputs are

82 higher.

83 In general, recipient populations generally show a positive relation in terms of growth,

84 density or population biomass as resource subsidy input rate increases. For instance, Swain et al.

85 (2014) showed a positive relation of invertebrate densities, algae and sculpin densities along a

86 gradient of long-term escapement numbers of spawning Sockeye Salmon in central British

87 Columbia. Wipfli and Musselwhite (2004) and Piccolo and Wipfli (2002) demonstrated higher

88 rates of invertebrate subsidies from upland forested streams to downstream habitats as riparian 
89 alder increased in coastal Alaska. Similarly, reductions in subsidy inputs can have negative

90 consequences for recipient ecosystems. Gergs et al. (2014) showed that densities of an invasive,

91 non-native amphipod in the Rhine River were negatively associated with the rates of emergence

92 of adult aquatic insects, and was linked to lower densities of terrestrial spiders.

\section{Quantitative effects of experimental manipulations}

95 There are many experimental studies of the addition or exclusion of a large diversity

96 cross-ecosystem resource subsidies. For instance, experimental additions (e.g., Richardson 1991)

97 or exclusion (e.g., Wallace et al. 1999) of leaf litter to streams have demonstrated that detritus is

98 an important subsidy resource for particular consumer populations and overall productivity of

99 streams. Additions or removal of sea wrack on small Caribbean islands has shown that this too

100 is a key resource affecting recipient populations (e.g., Piovia-Scott et al. 2011). Exclusion of

101 terrestrial arthropods from dropping into a stream resulted in reduced growth and shifts in

102 foraging by trout (Nakano et al. 1999), and exclusion of nematomorph-infected crickets from

103 streamsides resulted in much lower growth rates of char compared to control reaches (Sato et al.

104 2011). Exclusion of adult aquatic insects from riparian areas show many web-building spiders

105 use this resource (Marczak and Richardson 2007). However, almost all of these manipulations

106 have been binary, i.e. addition or exclusion of some cross-ecosystem resource subsidy relative to 107 an ambient "control".

108 Some examples of manipulations to create experimental gradients of subsidy input rates

109 have appeared in recent years. Wipfli et al. $(1998,1999)$ demonstrated that biofilm growth and

110 densities of benthic invertebrates were positively related to the amount of salmon carcass added

111 to experimental streams in Alaska. Manipulation of input rates of periodical cicadas to pond 
112 mesocosms demonstrated a positive response of biofilms and consumers along the input gradient

113 (Nowlin et al. 2007). Klemmer and Richardson (2012) created a gradient of leaf litter abundance

114 in cages in a lake with or without trout present, and demonstrated a positive and generally

115 asymptotic response in the numbers of detritivores. Jones and Lennon (2015) created an

116 experimental gradient in the concentrations of dissolved organic carbon (DOC) in a series of

117 ponds, which led to increased bacterial productivity along that concentration gradient, although

118 overall system productivity was hump-shaped due to the light attenuation effect of colored DOC

119 and reduced primary productivity. What is missing from the literature is a more general

120 predictive framework of how populations could respond to quantitative differences or variation

121 in the input rates of subsidy resources.

122 Yang et al. (2008) and Holt (2008) have developed models to predict how the subsidy

123 pulse duration relative to the generation time of the consumer, as well as the pulse magnitude

124 would result in consumer population responses. Many studies have used short-term pulses in

125 experiments. However, we still need to do more to scale these subsidy pulses in ways that can be

126 incorporated into consumer-resource dynamics and models, such as those mentioned above

127 (Yang et al. 2008; Holt 2008).

128

129 Conversion efficiency: another way of looking at responses to subsidies

130 The majority of these studies have not considered the rates of increase in the relations of

131 consumer population response relative to subsidy inputs in terms of whether they are

132 proportional to some conversion rate such as assimilation efficiency. That is, one might be able

133 to examine the slope of the input rate (energy or biomass) versus response (functional response

134 or numerical response) of consumer biomass. By definition the slope must be $<1.0$, but the slope 
135 would be predicted to be very much smaller than 1.0 for detritivores than for stream fishes eating

136 terrestrial prey. For instance, Mehner et al. (2016) found that consumers incorporated only 5\%

137 of inputs of particulate organic matter to lakes, a very low ecological efficiency. Such uses of

138 conversion efficiencies are common to ecosystem energetics models. However, to date this

139 approach has not been used much for quantifying responses of recipient consumer populations to 140 subsidy resources.

\section{Alternate trajectories of consumer population responses to subsidy input rates}

143 As discussed above, experimental studies of resource subsidies have primarily used

144 exclusion or addition of a single treatment level to test for recipient consumer responses. From

145 such studies, one would initially draw a straight line from the ambient rates to the manipulated

146 rates, with relatively little consideration of how the responses might vary with response to

147 different rates of subsidy inputs (Figure 1). As a first approximation this first model assumes a

148 linear response over the natural range of subsidy inputs. Few studies have considered whether

149 these relations are linear across the full range of natural variation of input rates, which might be

150 unlikely as other processes begin to limit or co-limit recipient responses, for instance, space

151 limitation or limitation by other resources, or even build up of predators and pathogens (Figure

152 1). This would lead to a non-linear response of consumer populations to increasing subsidy input

153 rates.

154 It is likely that the shape of the consumer populations' response surface might be

155 asymptotic as our second suggested curve (Figure 1), as proposed by Richardson (1993). Several

156 examples of such relations have been published. Wipfli et al. (1999) experimentally

157 demonstrated an asymptotic response of algae and freshwater invertebrates to incremental 
158 increases of salmon subsidies in experimental channels and a small natural stream in Alaska.

159 Dose-response relationships at broader spatial and temporal scales would advance our

160 understanding of quantitative subsidy effects on consumers and ecosystems.

As a third option, response surfaces to subsidy inputs could be sigmoid, which would line

162 up with the large literature on prey switching found in the predation literature (e.g., Townsend et

163 al. 1986). The switching curve (sigmoid) may reach an asymptote for many potential reasons,

164 the most obvious would be the co-limitation of other variables (as in model 2 above), but could

165 also be limited by functional responses within generations of longer-lived recipient species, or

166 even by top-down control by predators. Sato and Watanabe (2014) showed that as input rates of

167 terrestrial prey increased, stream fishes switched from in situ prey to the terrestrial prey, but at

168 low prey input rates they did not feed on subsidy prey.

169 Another potential recipient response function to subsidy inputs could be hump shaped,

170 stimulating at low input rates and toxic at high rates (Figure 1), consistent with the subsidy-stress

171 gradient hypothesis. This hypothesis was proposed for the non-linear responses in a population

172 or community across a gradient of inputs (Odum et al. 1979). Most of these inputs were regarded

173 as stimulating to recipient systems at low to moderate input rates, but stressful at higher input

174 rates leading to deceleration of the productivity of the recipient. The form of this relation is

175 shown as a hump-shaped response curve along the gradient. It is easy to appreciate this when

176 one considers the inputs of nutrients which could be stimulating at low concentrations, assuming

177 a nutrient-limited system, and becoming toxic at high concentrations (Odum et al. 1979). For

178 instance, an example of this is to be found in Woodward et al. (2012) showing that modest inputs

179 of nutrients ( $\mathrm{N}$ and $\mathrm{P}$ ) to streams stimulated decomposition rates of terrestrial leaf litter and input

180 to food webs, whereas high concentrations decreased decomposition rates, presumably through 
181 toxicity of high $\mathrm{N}$ concentrations. Another example of this hump-shaped response surface was

182 demonstrated in an experimental manipulation of DOC to ponds (Jones and Lennon 2015). In

183 that experiment increased concentrations of DOC led to increases in bacterial production

184 increasing along the entire gradient of DOC additions. However, the increase in microbial

185 production was more than offset in the other direction by light attenuation due to the colored

186 DOC, and thus beyond a peak response at low concentrations of DOC, measures of zooplankton,

187 chlorophyll $a$ and respiration declined due to reduced primary production (Jones and Lennon

188 2015). Another example where a potential marine subsidy can become lethal comes from

189 Southeast Alaska and shows how too many returning adult pink salmon can rapidly deplete

190 stream $\mathrm{O}_{2}$ concentrations (Leon Shaul, Alaska Dept of Fish and Game, personal communication)

191 (Figure 2). In this case not only does the potential subsidy die prior to spawning, but it causes

192 extensive mortality in the recipient consumers (juvenile coho salmon in this case). Although

193 apparently rare, these types of die-offs appear to be happening more frequently in some areas

194 with strong salmon returns, coupled with warm and sunny (summer), low-water periods.

195 It is possible that there could be other consumer-resource responses for recipient

196 populations, but these four cover the primary dynamical outcomes. Of course, there are many

197 potential higher-order consequences at a community level, driven through trophic and indirect

198 interactions. For instance, terrestrial arthropods eaten by stream fishes can lead to trophic

199 cascades as pressure on in situ resources is relaxed (e.g. Nakano et al. 1999; Sato et al. 2016).

200 Additional prey as a result of sea wrack can reduce predation pressure by island lizards on

201 herbivorous insects leading to indirect effects from a subsidy resource at the shoreline resulting

202 in benefits to plants (Piovia-Scott et al. 2011). There are several other very good examples of

203 community-level effects, directly and indirectly resulting from subsidy inputs, but it is not our 
204 purpose to review all those here. Resource subsidies could also be potentially destabilising as

205 biomass of a subsidised population returns to feeding on in situ resources and potentially over-

206 consuming instantaneous production (Yang et al. 2008). Nowlin et al. (2007) and Jones and

207 Lennon (2015) showed that increased subsidy inputs (cicada carcasses and DOC concentration,

208 respectively) resulted in decreased stability across an intermediate level of subsidy input rates. A

209 large range of community and ecosystem-level dynamics may be influenced by cross-ecosystem

210 resource subsidies, and this is a topic for continuing research.

211

212 In Richardson and Sato (2015) there were 5 key questions posed regarding future

213 directions of the study of cross-ecosystem resource subsidies. These included questions of

214 duration and magnitude (e.g., Yang et al. 2008), resource quality (size, nutritional value,

215 protective chemicals, etc. (e.g., Marcarelli et al. 2011)), influence on intensity of trophic

216 cascades, and impacts on recipient system stability. The final question was about quantitative

217 predictions, the subject of this special issue of the Canadian Journal of Fisheries and Aquatic

218 Sciences. We now have sufficient knowledge of these processes that we should be able to

219 become more quantitative about our predictions and in our studies of consumer population

220 responses.

\section{Special Issue}

223 In this special issue we include eight papers presented at a special symposium of the annual

224 American Fisheries Society meeting in August, 2015. These papers present examples of

225 consumer responses to cross-ecosystem resource subsidies, including to and from streams and

226 lakes. All of these papers involve either fish as the recipient consumer or their carcasses as the 
227 subsidy, and these studies demonstrate the range of ways subsidy resources affect consumer 228 populations and their communities.

Although there have been many studies of cross-ecosystem resource subsidies with

230 salmonids either as the subsidy (carcasses of anadromous species) or the consumer, they are not

231 the only group of fishes that are involved in these dynamics. As Weaver et al. (this issue) show,

232 Atlantic lamprey returning to east coast streams can contribute to a pulse subsidy of nutrients and

233 biomass to streams. Weaver et al. (this issue) demonstrated that experimental additions of

234 lamprey carcasses along a stream reach enhanced the local productivity of a stream food web by

235 alleviating nutrient limitation of biofilms through increased $\mathrm{N}$ as ammonium from the carcasses.

236 Moreover, along their experimental study reach they were able to show increasing concentrations

237 of ammonium as the cumulative totals of lamprey carcasses increased, with concomitant patterns

238 in algal biomass. The slope of the line relating algal biomass to cumulative lamprey biomass

239 was very shallow $(<<1)$ suggesting other factors limited the potential for this subsidy to limit the 240 potential for increases due the subsidy inputs.

241 Subsidies are not just important in small streams. As Rine et al. (this issue) demonstrated,

242 terrestrial (invertebrates) and marine (salmon carcasses) subsidies provide measurable trophic

243 contributions to juvenile Coho Salmon and Chinook Salmon along a 97-km stretch of a large,

244 complex glacial river in Alaska. These contributions varied relative to each other and seasonally,

245 and were secondary to freshwater food resources, with the main periods of benefits during

246 summer and early autumn. Moreover, the relative contributions of these subsidy resources

247 varied spatially along habitat units in this large and complex river, and illustrates the importance

248 of considering the broader portfolio of energy and nutrient sources and type, and how they vary

249 across time and space. Most past studies have not taken into account this broader quantitative 
250 view of prey source and utilization across complex habitat mosaics of large floodplain rivers, as

251 shown by Rine et al. (this issue). Li et al. (this issue) also provide evidence for spatial variation

252 (tributaries versus larger streams) and a strong seasonal difference in biomass of terrestrial

253 invertebrates ingested (mass-specific rates) by cutthroat trout and steelhead, despite no sign of

254 differences in growth rates as a result.

255 Mejia et al. (this issue) used experimental enclosures to assess juvenile Chinook Salmon

256 growth at areas identified as groundwater inflow, streamwater outflow, or neutral sites to factor

257 out temperatures, nutrients and DOC as variables that could contribute to groundwater impacts

258 on instream productivity. Fish enclosed at groundwater inflows had nearly twice the growth rate

259 of fishes at the losing sites, supported by much higher GPP and benthic biomass, as well as by

260 warmer temperatures in this spring-time experiment. This provides another example of how the

261 physical environment interacts with subsidy resources to influence responses of recipient

262 consumers.

263 Smits et al. (this issue) found that growth rates of Coho Salmon juveniles were related to

264 presence of Sockeye Salmon carcasses (and their eggs), but that the response was modulated by

265 stream temperatures. By using several years' worth of data across seven streams with natural

266 variation in temperatures and Sockeye spawner densities, they used this natural variation to link

267 subsidy supplies and temperatures to consumer responses. However, density of spawning

268 Sockeye Salmon was not a significant contributor to Coho responses, only the presence or

269 absence of Sockeye spawners, which also contrasts with several past studies (e.g. Wipfli et al.

270 1998, Swain et al. 2014). This exemplifies that additional controls from the physical

271 environment can interact with the subsidy input rates to influence the recipient population's

272 response through variation in allocation of energy. 
273

274

275

276

277

278 279 related to weather.

280

281

282

283

284

285

286 287 stream.

288

289

290

291

292

293

294

295

Boucek et al. (this issue) demonstrate that the rate of subsidy flows into rivers in Florida can vary as a consequence of annual weather patterns due to drought influencing distribution and abundance of invertebrate prey in floodplains that can enter the river. In floodplain river systems, fishes can exploit the floodplain during wet seasons, but following an extreme drought

year, the biomass and types of prey available from floodplains was reduced by over $75 \%$. This provides another example of controls of resource subsidies at the level of the donor system

Changes in the quality and quantity of subsidies to streams of leaves and terrestrial invertebrates due to shifts in riparian species composition have been shown (e.g. Wipfli 1997, Marcarelli et al. 2011). Roon et al. (this issue) provide another example of how non-native species of riparian trees can alter the quantity (and perhaps timing) of terrestrial invertebrate inputs. Surprisingly, despite much lower input rates of terrestrial invertebrates in reaches with European Birdcherry, Roon et al. (this issue) found no significant differences in feeding rates of Coho Salmon juveniles in their Alaska streams, likely due to prey mixing above and within the

Piovia-Scott et al. (this issue) develop a broad, conceptual model of the influence of two factors, trout presence and elevation, on the relative rates of fluxes of cross-ecosystem resources for lakes in the mountains of California. They demonstrate that elevation and fish presence (most often purposefully introduced) account for the majority of variance in a set of data for subsidy fluxes into and out of lakes. In their paper they provide quantitative estimates of fluxes of resource subsidies in both directions, to and from the lake ecosystems and consider the main hypotheses for the mechanisms by which these flows vary by trout presence and elevation (Piovia-Scott et al. this issue). 


\section{Discussion}

As a more coherent body of theory develops around the consumer-resource dynamics of donor-controlled subsidy inputs, we should be able to develop a more quantitative approach to

300 the interaction. Theory by Yang et al. (2008) and Holt (2008) scale inputs of subsidy resources

301 by the magnitude and duration of the inputs relative to the consumer resource demand and

302 generation time of the consumers, respectively. This kind of quantification is still missing from

303 a great deal of the empirical research, although Marczak et al. (2007) used a meta-analysis to

304 look at how the relative magnitude of inputs affected consumer populations. Rine et al. (this

305 issue) have taken a step towards quantifying this for river salmonids, building on similar efforts

306 by Wipfli and Baxter (2010). Further development of scaling properties will enable us to

307 advance the ability to predict consumer population responses.

308 Emerging examples are suggesting that recipient responses are not simple and may interact

309 with other factors, such as interactions in effect sizes from both concentrations and stoichiometry

310 of nutrients in freshwater (Guesewell and Gessner 2009; Bellmore et al. 2014). And consumers

311 vary in the types and sizes of subsidy resources they can use, illustrating that even within

312 species, size classes may respond differently (e.g., Marczak et al. 2007b, Li et al. this issue,

313 Piovia-Scott et al. this issue, Smits et al. this issue). In addition, the seasonal timing of subsidy

314 inputs might be important to the responses by consumer populations (e.g. Sato et al. 2016).

315 Resource quality may be an important additional factor. There have been many studies

316 over the years of how differences in leaf litter quality affects breakdown rates and rates of

317 consumption by consumers. Knowing input rates, along with quality, may enable us to better

318 predict the consequences for productivity of consumer populations. This likely extends to the 
319 species of terrestrial invertebrates falling into streams, and changes to the complement of species

320 falling depending on the type of vegetative canopy, for instance as seen in Roon et al. (this

321 issue). Quality may include nutritional quality, but it can also include size. For instance, large

322 prey may be differentially eaten in contrast to smaller prey (e.g. Marczak et al. 2007b, Li et al.

323 this issue).

324 Studies of cross-ecosystem resource subsidies often note that there are flows of resources

325 in both directions across boundaries. These are rarely reciprocal in the sense of creating a

326 positive feedback loop. However, it is rare to have detailed studies such as that Piovia-Scott et al.

327 (this issue) provide, estimating how these flows vary into and out of lakes based on trophic

328 structure (presence of trout) and elevation. More system-wide and quantitative studies of flows

329 in both directions would be informative, as well as explicit consideration of the full range of

330 direct and indirect effects within communities.

331 The field still needs to develop additional studies to look at the form of the response curves

332 of recipient consumers to different rates of subsidy flows. There is an opportunity to advance the

333 theory in the context of consumer-resource dynamics, and consider the additional feedbacks on

334 population controls associated with co-limitation, density dependence, and additional community

335 interactions, such as predation rates. Cross-ecosystem resource subsidies provide a potentially

336 powerful experimental model for learning about consumer-resource dynamics in a donor-

337 controlled system, where the resource input rates to the system are not controlled by the

338 consumer.

339 Changes in the timing, magnitudes, and quality of resource subsidy flows due to land use,

340 climate change, and invasive species could lead to unpredicted, and potentially unwanted,

341 outcomes for consumers and their communities. For instance, the temperature dependence of 
342 juvenile salmon responses to salmon carcasses (Smits et al. this issue) or groundwater inflows

343 (Mejia et al. this issue), or the change in terrestrial arthropod inputs from invasive, non-native

344 plants taking over riparian areas (Roon et al. this issue) are just a couple of examples of how

345 impacts of resource subsidies could be altered. This match-mismatch hypothesis has been the

346 focus of a great deal of climate change research, and the potential for shifts in the phenology of

347 cross-ecosystem resource subsidy flows as a result of changes to plant composition and climate

348 change might also alter the responses of recipient populations.

349 The community and food-web effects of subsidies are being increasingly noted. As several

350 authors have demonstrated, subsidies (or their exclusion) can lead to trophic cascades and other

351 community level impacts (e.g. Nakano et al. 1999; Sato et al. 2016). There are certainly many

352 examples of subsidies boosting production at lower trophic levels that contribute to bottom-up

353 increases at higher trophic levels (e.g. Wallace et al. 1999; Wipfli et al. 1999). Other

354 considerations of how subsidies might contribute to, or reduce, stability are emerging (e.g.

355 Rosenzweig 1971; Nowlin et al. 2007; Jones and Lennon 2015).

356 Appreciation of the roles of cross-ecosystem resource subsidies as a flow to recipient

357 consumers requires that one correctly identify what limits populations in the first place. At some

358 input rates subsidy resources are predicted to become excess and consumer population responses

359 would be asymptotic, or even hump-shaped. However, resource subsidies may have no impact

360 on consumers if equivalent resources are available and not limiting. In many instances, other

361 resources might be the primary constraint on consumer populations, or other resources may be

362 co-limiting (e.g. Sperfeld et al. 2016). The latter does lead to the question of how such resource

363 flows might contribute to the recipient community if the target consumer does not use them. It is

364 worth considering other consumers and pathways for these resource flows even when the 
365 putative target consumer shows no response. Better understanding the interactions of subsidy

366 resources with constraints based on other resources would be another possible research need.

367 The papers in this special issue address some of the large range of possible responses by

368 consumer populations. There is still a large scope for advancing this field by linking subsidy

369 resources to consumer-resource dynamics and considering how input rates affect population and

370 community responses depending on rates and quality of inputs, as well as aspects of timing

371 relative to consumer life cycles and duration of the inputs. Quantitative models can provide a

372 tool to consider how subsidy inputs to one trophic level might influence the dynamics at the

373 community level, since most published studies are of durations too short to adequately determine

374 responses at other trophic and ecosystem levels, and longer-term effects.

\section{Acknowledgements}

377 We thank the many reviewers who commented on the earlier versions of papers included here.

378 We are grateful to Ryan Bellmore for his detailed review of our manuscript. We also thank Leon

379 Shaul and Amy Hemenway with Alaska Dept of Fish and Game for use of photos and their

380 insights on relationships between subsidy input rates, water temperature, biological oxygen

381 demand, and juvenile salmon mortality. Our research is funded by grants from the Natural

382 Sciences and Engineering Research Council (Canada) to JSR, and from US Geological Survey

383 and NSF-EPSCoR to the University of Alaska.

385 References 
386 Bellmore, J.R., Fremier, A.K., Mejia, F., and Newsom, M. 2014. The response of stream

387 periphyton to Pacific salmon: using a model to understand the role of environmental context.

$388 \quad$ Freshwat. Biol. 59: 1437-1451.

389 Boucek, R.E., Soula, M., Tamayo, F., and Rehage, J.S. A once in ten year drought alters the

390 magnitude and quality of a floodplain prey subsidy to coastal river fishes. Can. J. Fish.

$391 \quad$ Aquat. Sci. this issue.

392 Gergs, R., Koester, M., Schulz, R.S., and Schulz, R. 2014. Potential alteration of cross-

393 ecosystem resource subsidies by an invasive aquatic macroinvertebrate: implications for the

394 terrestrial food web. Freshwat. Biol. 59: 2645-2655.

395 Guesewell, S., and Gessner, M.O. 2009. N : P ratios influence litter decomposition and

396 colonization by fungi and bacteria in microcosms. Functional Ecol. 23: 211-219.

397 Holt RD. 2008. Theoretical perspectives on resource pulses. Ecology 89: 671-681.

398 Jones, S.E., and Lennon, J.T. 2015. A test of the subsidy-stability hypothesis: the effects of

399 terrestrial carbon in aquatic ecosystems. Ecology 96:1550-1560.

400 Klemmer, A.J., and Richardson, J.S. 2013. Quantitative gradient of subsidies reveals a threshold

401 in community-level trophic cascades. Ecology 94: 1920-1926.

402 Li, J., Gerth, W., Van Driesche, R., Bateman, D., and Herlihy, A. Seasonal and spatial

403 fluctuations in Oncorhynchus trout diet in a temperate mixed-forest watershed. Can. J. Fish.

$404 \quad$ Aquat. Sci. this issue.

405 Marcarelli, A.M., Baxter, C.V., Mineau, M.M., and Hall, R.O. Jr. 2011. Quantity and quality:

406 unifying food web and ecosystem perspectives on the role of resource subsidies in

407 freshwaters. Ecology 92: 1215-1225. 
408 Marczak, L.B., and Richardson, J.S. 2007. Spiders and subsidies: results from the riparian zone 409 of a coastal temperate rainforest. J. Anim. Ecol. 76: 687-694.

410 Marczak, L.B., Thompson, R.M., and Richardson, J.S. 2007a. A meta-analysis of the role of 411 trophic position, habitat type and habitat productivity in determining the food web effects of 412 resource subsidies. Ecology 88:140-148.

413 Marczak, L.B., Hoover, T.M., and Richardson, J.S. 2007b. Trophic interception: how a 414 boundary-foraging organism influences cross-ecosystem fluxes. Oikos 116:1651-1662.

415 Mehner, T., Attermeyer, K., Brauns, M., Brothers, S., Diekmann, J., Gaedke, U., Grossart, H.-P., 416 Köhler, J., Lischke, B., Meyer, N., Scharnweber, K., Syväranta, J., Vanni, M.J., and Hilt, S. 417 2016. Weak response of animal allochthony and production to enhanced supply of 418 terrestrial leaf litter in nutrient-rich lakes. Ecosystems 19: 311-325.

419 Mejia, F.H., Baxter, C.V., Berntsen, E.K., and Fremier, A.K. Linking groundwater-surface water 420 exchange to food production and salmonid growth. Can. J. Fish. Aquat. Sci. this issue.

421 Nakano, S. Miyasaka, H., and Kuhara, N. 1999. Terrestrial-aquatic linkages: Riparian arthropod 422 inputs alter trophic cascades in a stream food web. Ecology 80: 2435-2441.

423 Nowlin, W.H., González, M.J., Vanni, M.J., Stevens, M.H.H., Fields, M.W., and Valente, J.J. 424 2007. Allochthonous subsidy of periodical cicadas affects the dynamics and stability of 425 pond communities. Ecology 88: 2174-2186.

426 Odum, E.P., Finn, J.T., and Franz, E.H. 1979. Perturbation theory and the subsidy-stress 427 gradient. BioScience 29: 349-352.

428 Piovia-Scott, J., Spiller, D.A., and Schoener, T.W. 2011. Effects of experimental seaweed 429 deposition on lizard and ant predation in an island food web. Science 331: 461-463. 
430 Piovia-Scott, J., Sadro, S., Knapp, R.A., Sickman, J., Pope, K.L., and Chandra, S. Landscape-

431 level variation in reciprocal subsidies between lakes and watersheds: Perspectives from the 432 mountains of California. Can. J. Fish. Aquat. Sci. this issue.

433 Polis, G.A., Anderson, W.B., and Holt, R.D. 1997. Toward an integration of landscape and food 434 web ecology: The dynamics of spatially subsidized food webs. Annual Review of Ecology 435 and Systematics 28: 289-316.

436 Richardson, J.S. 1993. Limits to productivity in streams: evidence from studies of 437 macroinvertebrates, p.9-15. In: Gibson, R.J., and Cutting, R.E. [Eds] Production of juvenile 438 Atlantic salmon, Salmo salar, in natural waters. Canadian Special Publication of Fisheries $439 \quad$ and Aquatic Sciences 118

440 Richardson, J.S., and Sato T. 2015. Resource flows across freshwater-terrestrial boundaries and 441 influence on processes linking adjacent ecosystems. Ecohydrology 8: 406-415.

442 Richardson, J.S., Zhang, Y., and Marczak, L.B. 2010. Resource subsidies across the land443 freshwater interface and responses in recipient communities. River Research and Applic. 26: $444 \quad 55-66$.

445 Richardson, J.S. 1991. Seasonal food limitation of detritivores in a montane stream: an $446 \quad$ experimental test. Ecology 72: 873- 887.

447 Rine, K.M., Wipfli, M.S., Schoen, E.R., Nightengale, T.L., and Stricker, C.A. Trophic pathways 448 supporting juvenile Chinook and coho salmon in the glacial Susitna River, Alaska: patterns 449 of freshwater, marine, and terrestrial food resource use across a seasonally dynamic habitat 450 mosaic. Can. J. Fish. Aquat. Sci. this issue. 
451 Roon, D.A., Wipfli, M.S., Wurtz, T.L., and Blanchard, A.L. Invasive European bird cherry

452 (Prunus padus) reduces terrestrial prey subsidies to urban Alaskan salmon streams. Can. J.

$453 \quad$ Fish. Aquat. Sci. this issue.

454 Rosenzweig, M.L. 1971. Paradox of enrichment: Destabilization of exploitation ecosystems in $455 \quad$ ecological time. Science 171:385-387.

456 Sato, T., and Watanabe, K. 2014. Do stage-specific functional responses of consumers dampen

457 the effects of subsidies on trophic cascades in streams? J. Anim. Ecol. 83:907-915.

458 Sato, T., Watanabe, K., Kanaiwa, M., Niizuma, Y. Harada, Y and Lafferty, K.D. 2011.

459 Nematomorph parasites drive energy flow through a riparian ecosystem. Ecology 92:201-

460207.

461 Sato, T., El-Sabaawi, R., Campbell, K., Ohta, T., and Richardson, J.S. A test of the effects of

462 timing of a pulsed resource subsidy on stream ecosystems. J. Anim. Ecol. in press

463 Sperfeld, E., Raubenheimer, D., and Wacker, A. 2016. Bridging factorial and gradient concepts

464 of resource co-limitation: towards a general framework applied to consumers. Ecology

$465 \quad$ Letters 19: 201-215

466 Smits, A.P., Schindler, D.E., Armstrong, J.B., Brett, M.T., Carter, J.L., and Santos, B.S. Thermal 467 constraints on stream consumer responses to a marine resource subsidy. Can. J. Fish. Aquat. $468 \quad$ Sci. this issue.

469 Swain, N. R., Hocking, M.D., Harding, J.N., and Reynolds, J.D. 2014. Effects of salmon on the 470 diet and condition of stream-resident sculpins. Can. J. Fish. Aquat. Sci. 71: 521-532.

471 Takimoto, G., Iwata, T., and M. Murakami. 2009. Timescale hierarchy determines the indirect 472 effects of fluctuating subsidy inputs on in situ resources. American Naturalist 173:200-211. 
473 Townsend, C.R., Winfield, I.J., Peirson, G., and Cryer, M. 1986. The response of young roach

$474 \quad$ Rutilus rutilus to seasonal changes in abundance of microcrustacean prey: a field

475 demonstration of switching. Oikos 46: 372-378.

476 Wallace, J.B., Eggert, S.L., Meyer, J.L., and Webster, J.R. 1999. Effects of resource limitation

477 on a detrital-based ecosystem. Ecol. Monogr. 69: 409-442.

478 Weaver, D., Coghlan, S., and Zydlewski, J. Sea Lamprey carcasses exert local and variable food

479 web effects in a nutrient-limited Atlantic coastal stream. Can. J. Fish. Aquat. Sci. this issue.

480 Wipfli, M.S. 1997. Terrestrial invertebrates as salmonid prey and nitrogen sources in streams:

481 contrasting old-growth and young-growth riparian forests in southeastern Alaska, USA. Can.

482 J. Fish. Aquat. Sci. 54: 1259-1269.

483 Wipfli, M.S., and Musslewhite, J. 2004. Density of red alder (Alnus rubra) in headwaters

484 influences invertebrate and detritus subsidies to downstream fish habitats in Alaska.

$485 \quad$ Hydrobiologia 520: 153-163.

486 Wipfli, M.S., and Baxter, C.V. 2010. Linking ecosystems, food webs, and fish production:

487 Subsidies in salmonid watersheds. Fisheries 35: 373-387.

488 Wipfli, M.S., Hudson, J., and Caouette, J. 1998. Influence of salmon carcasses on stream

489 productivity: response of biofilm and benthic macroinvertebrates in southeastern Alaska,

490 U.S.A. Can. J. Fish. Aquat. Sci. 55: 1503-1511.

491 Wipfli, M.S. Hudson, J.P., Chaloner, D.T., and Caouette, J.R. 1999. Influence of salmon

492 spawner densities on stream productivity in Southeast Alaska. Can. J. Fish. Aquat. Sci.

$493 \quad 56: 1600-1611$.

494 Woodward, G., Gessner, M.O., Giller, P.S., Gulis, V., Hladyz, S., Lecerf, A., Malmqvist, B., 495 McKie, B.G., Tiegs, S.D., Cariss, H., Dobson, M., Elosegi, A., Ferreira, V., Graca, M.A.S., 
496 Fleituch, T., Lacoursiere, J.O., Nistorescu, M., Pozo, J., Risnoveanu, G., Schindler, M.,

497 Vadineanu, A., Vought, L.B-M., and Chauvet, E. 2012. Continental-scale effects of nutrient 498 pollution on stream ecosystem functioning. Science 336: 1438-1440.

499 Yang LH, Bastow JL, Spence KO, Wright AN. 2008. What can we learn from resource pulses?

$500 \quad$ Ecology 89: 621-634.

501 
Figure captions:

504 Figure 1. Possible response surfaces of recipient populations (biomass, numbers or productivity)

505 along a gradient of cross-ecosystem resource subsidy input rate. Dashed black line indicates the

506 default outcome one derives from two points, assuming a linear consumer response to increases

507 in subsidy input rates. The asymptotic red, solid line shows the potential pattern as some other

508 resource or process becomes limiting or co-limiting to recipient consumers. The dashed magenta

509 line indicates an expected response from a switching consumer (behavioral switch to subsidy

510 resource as input rates increases). Finally, the green (dashed and dotted) line is consistent with

511 the subsidy-stress hypothesis or other mechanism by which too much of a subsidy resource input

512 could have negative consequences on population productivity.

514 Figure 2. Example of the impacts of too much subsidy leading to lethal outcomes, in this case

515 through returning adult salmon exhausting the oxygen supply in a stream, killing spawning

516 adults (the subsidy) and the resident juvenile Coho Salmon (the potential recipient). Photos

517 courtesy of Amy Hemenway. 


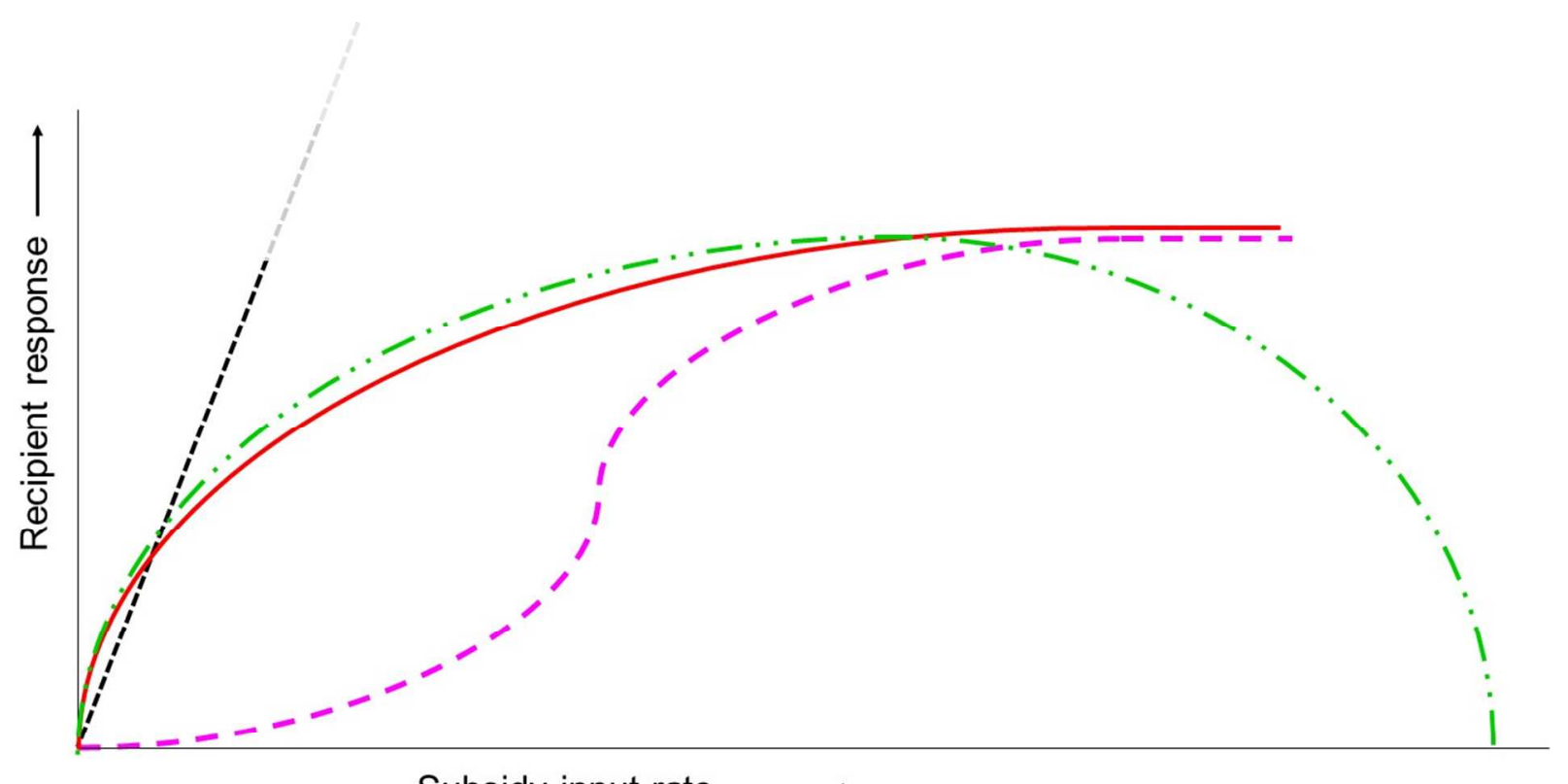

522 Figure 1. Possible response surfaces of recipient populations (biomass, numbers or productivity)

523 along a gradient of cross-ecosystem resource subsidy input rate. Dashed black line indicates the

524 default outcome one derives from two points, assuming a linear consumer response to increases

525 in subsidy input rates. The asymptotic red, solid line shows the potential pattern as some other

526 resource or process becomes limiting or co-limiting to recipient consumers. The dashed magenta

527 line indicates an expected response from a switching consumer (behavioral switch to subsidy

528 resource as input rates increases). Finally, the green (dashed and dotted) line is consistent with

529 the subsidy-stress hypothesis or other mechanism by which too much of a subsidy resource input

530 could have negative consequences on population productivity. 

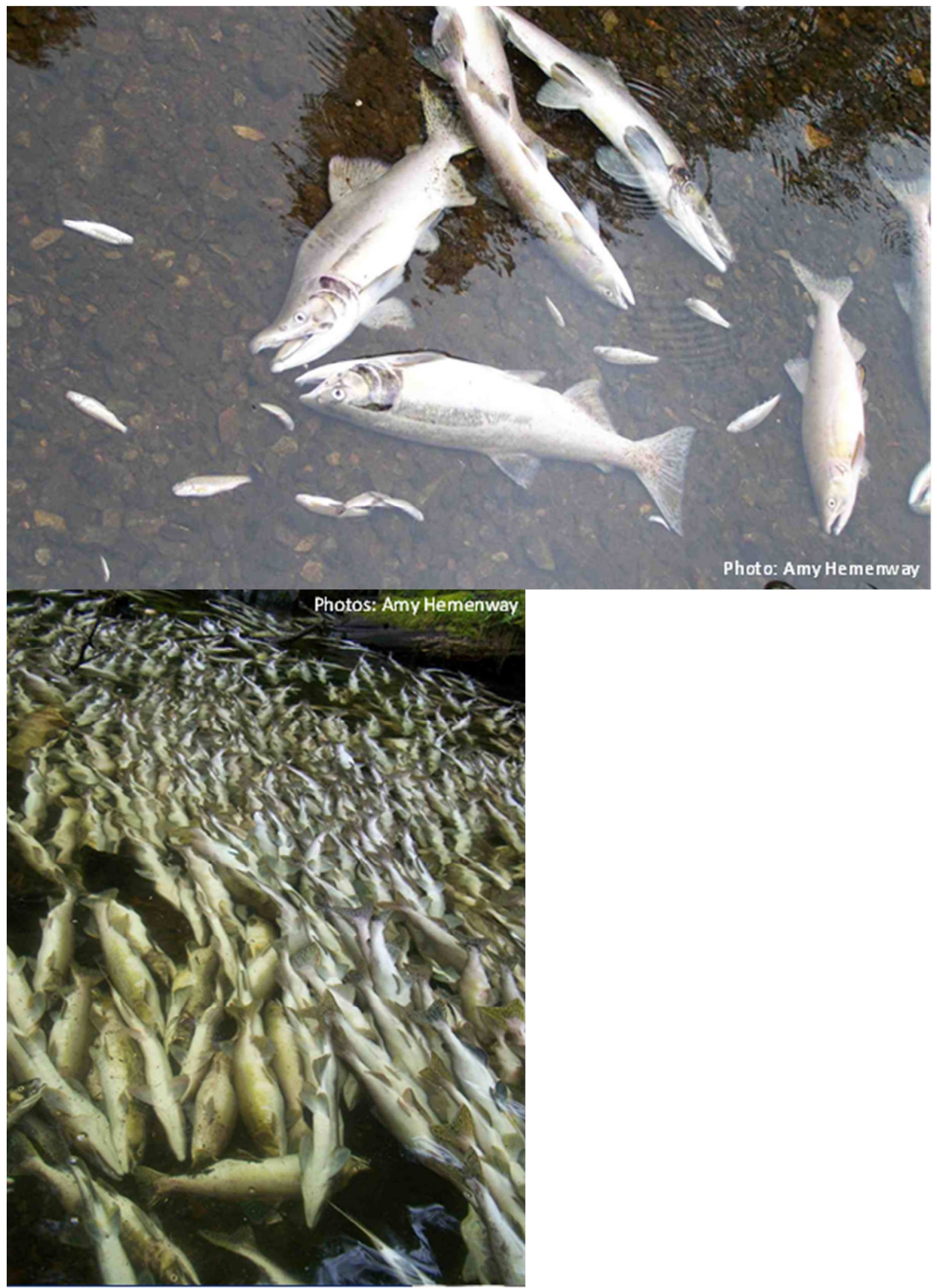
534 Figure 2. Example of the impacts of too much subsidy leading to lethal outcomes, in this case

535 through returning adult salmon exhausting the oxygen supply in a stream, killing spawning

536 adults (the subsidy) and the resident juvenile Coho Salmon (the potential recipient). Photos

537 courtesy of Amy Hemenway. 